Amongst predaceous enemies is mentioned a Chrysopa which feeds upon eggs and young larvæ. Wasps appear to do most good. Numerous parasites are also described; one, Trichogramma pretiosa, a small hymenopteron, attacks the eggs, others the larvæ; but from what we

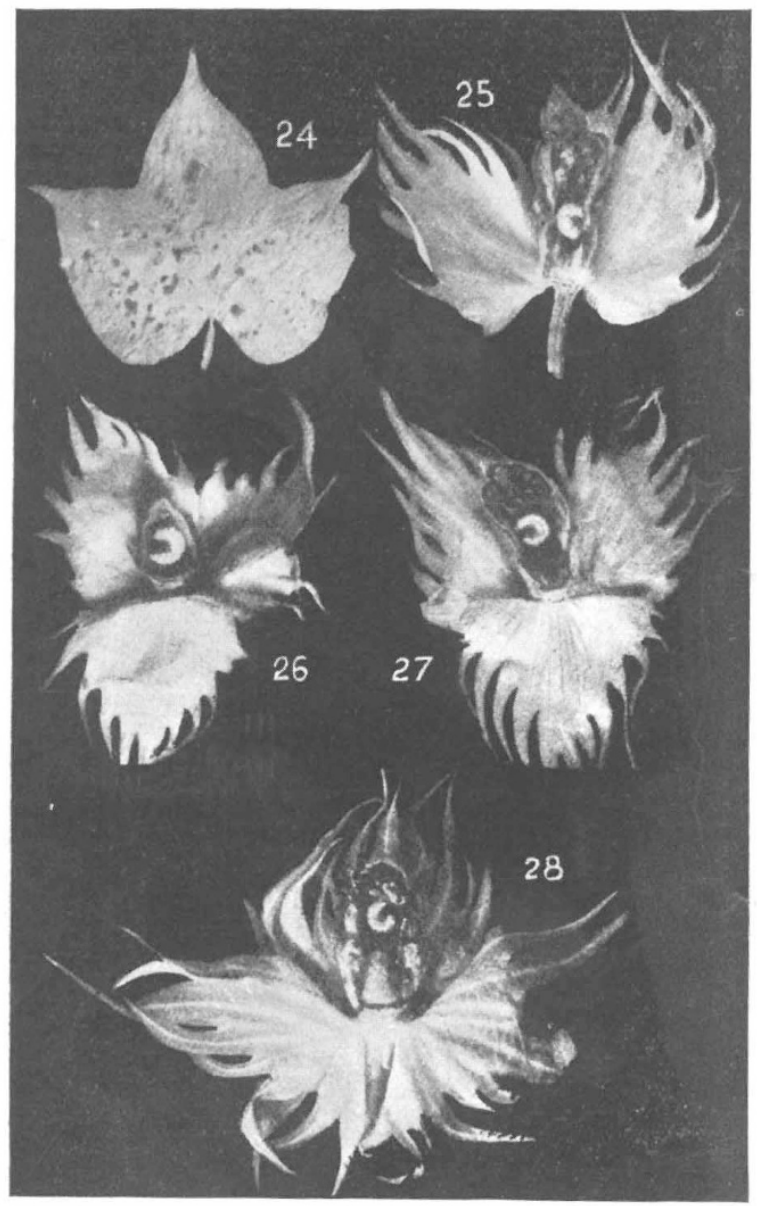

FIG. 2.-Various Results of Larval Work. 24 , I.eaf fed on extensively by weevils in confinement; 25 , full-grown larva in square ready to bloom 26, full-grown larva in square of usual size; 27 , larva full-grown, ovary in square entirely destroyed 28 , larva full grown, ovary untouchedall reduced (original).

gather from the report man cannot expect much help from these "natural checks." Remedial and preventive cultural measures are thus fully explained.

The Mexican cotton boll weevil is luckily confined to the United States, Mexico, Cuba, and Guatemala. The authors have been unable to verify the reports that it has been found in Africa or Brazil. If a cotton weevil occurs in the former country it is probably another species, as we see is the case in the Philippine Islands.

The Mexican weevil has the unique record of developing in less than twenty years from an obscure species into a great pest. The authors ably describe its life-history and destructive habits in Texas and elsewhere. In the summary of the life-history it is stated that the egg is deposited by the female in a cavity formed by eating into a square or boll. The egg hatches in a few days, and the footless grub begins to feed, making a larger chamber for itself as it grows. The pupa also occurs in the boll. It is important to note that no other food than cotton has been found.

Some interesting experiments are recorded which tend to show that the weevils are not able to locate their food by smell.

Another series of experiments showed that the weevils NO. I 889 , VOL. 737 prefer Egyptian cotton (Mit Afifi) to the American upland cotton.

Their capacity for reproduction seems appalling, judging from the table given showing the annual progeny of one pair of hibernating weevils, which amounts to 12,755 , 100!

The beetles hibernate in many places, as in infected bolls and stalks, and it is shown that the early destruction of the stalks in the fall is the most effective way to reduce the pest.

Dissemination takes place in cotton in bales and that sent for "ginning." Shipments of seeds are said to be almost certain to carry weevils if coming from infested areas. The report also shows another important point, namely, that the pilosity of the plant affects the progress of the weevil. Parasites do not seem to be of much use. Doubt is cast by the authors upon the benefit of Pedi culoides ventricosus. Mention is also made of the possible use of the Mexican ants (Ectotomma tuberculata), \&c. Of great importance to those who import seed is the result showing that bisulphide of carbon is the best substance to clean the seed.

Fred. V. THeOBaLd.

\section{THE GREAT GNOMON OF FLORENCE CATHEDRAL.}

A LTHOUGH numerous Christian churches are eithe oriented or adorned with reference to some astronomical phenomenon; there are few of such direct interest to the astronomer as the magnificent cathedral of Florence, which contains a gigantic contrivance for determining the advent of the summer solstice. We refer to the famous gnomon, placed in the dome of that cathedral by Paolo Toscanelli about the middle of the fifteenth century, and

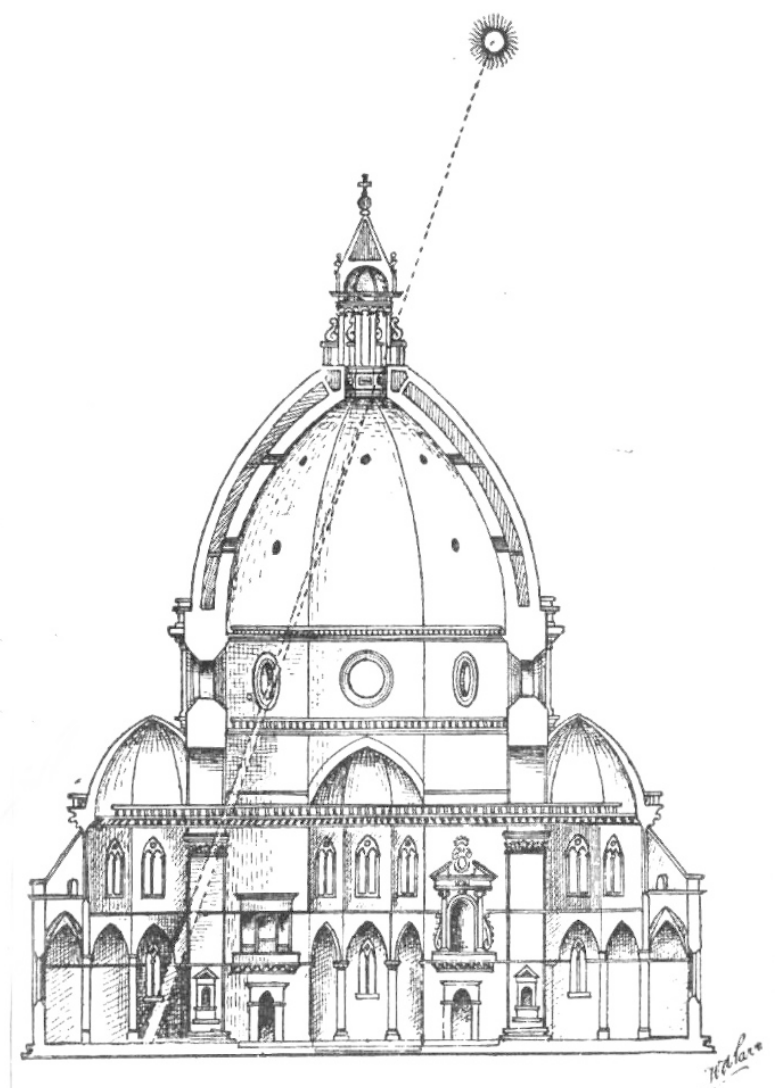

described and illustrated by Mr. W. A. Parr in the December number of Knowledge and Scientific News.

Lalande in 1765 referred to this instrument as "la méridienne que l'on voit dans la Cathédrale de Florence est le plus grand monument d'Astronomie qu'il y ait au 
monde," but at that time the astronomical significance of the Egyptian temples, or even of our own less pretentious Stonehenge, had not been demonstrated.

Sir Norman Lockyer has shown in "The Dawn of Astronomy" that the enormous edifice at Karnak, the temple of Amen-Ra, was oriented for a similar purpose, so that at the setting of the sun on the day of the solstice, atd at that time only, the solar beam flashed along the darkened axis of the temple, some 500 yards long, and illuminated the "holy of holies" wherein the priest was ready to fulfil the rites of "the Manifestation of Ra." $\mathrm{He}$ has also shown that Stonehenge was erected for a similar purpose about the year 1680 B.C., but in this case the limb of the actual (rising) sun was observed, the avenue simply forming the sight-line to the point on the horizon where the sun-god would make his first appearance on the day of the solstice.

But although since Lalande made the statement quoted above it has been shown that the gnomon at Florence is not the largest monument to astronomy the world has ever seen, it is still one of the most interesting. As may be gathered from the accompanying illustration, the sunlight, passing through the southern window of the lantern, falls on to the gnomon, which is built into the marble sill of the window, and thence, through a circular orifice, on to a "solstitial" marble slab let into the cathedral floor some 300 feet below, where its correct position at the solstice is marked, or was intended to be marked.

This immense meridian instrument was probably designed by Toscanelli in order to provide exact observations for the correction of the Alphonsine tables which were then in use, but which represented very inadequately the solar motion, more especially as regards the true length of the tropical year. Whether he also intended to observe the variation of the obliquity of the ecliptic is a much discussed question, but it does not seem improbable. In either case his gnomon, probably built only in 1468 A.D., could not answer this purpose anything like so surely as do the Amen-Ra and Stonehenge structures, built many centuries earlier. Apart from this reason, the facts that the gnomon itself has been removed from its original position, and that the solstitial circle on the cathedral floor has been found to be erroneously placed, have destroyed for ever the instrument's utility in this direction. It has been used, however, in order to detect any possible movement in the fabric of the cathedral, but, to the credit of Brunelleschi, who built the structure, no such movement has ever been demonstrated.

In the light of the recent articles in NATURE (p. 153) concerning the fires, \&c., by which the ancient British festivals were celebrated, it is interesting to note that $\mathrm{Mr}$. Parr considers that the great display of fireworks, which to the modern Florentine forms the chief attraction of the Midsummer Day festival, is simply the analogue of the "St. John's Fires" kindled in former times to celebrate the advent of the summer solstice. On that day huge crowds of Florentines flock to the cathedral in order to celebrate the festival of their patron saint, St. Giovanni, and at night the great dome itself is illuminated.

W. E. R.

THE TRAINING OF THE BODY AND MIND.

FOR years the London County Council has arranged a conference of teachers during January, and this time it was held on January $4-6$ at the Medical Examination Hall on the Victoria Embankment. In the old days, when the County Council was only interested in technical instruction, the meetings were devoted to the interests of science teachers more particularly, but now that general education has been added to the responsibilities of the body that governs London, matters appertaining to all kinds of teaching are considered at the conferences.

The first day's work was, however, devoted to a subject that affects all education, namely, that training of the body which is correlated with the proper development of the mind. Mr. A. J. Shepheard (vice-chairman of the education committee of the London County Council), who opened the conference, urged the importance of a complete education, and Colonel Malcolm Fox (inspector of physical No. I 889 , VOL. 73] training to the Board of Education) read the first paper, which dealt more particularly with physical training in elementary schools. He began with a brief sketch of the history of gymnastics and physical culture in general, though going no further back than the days of ancient Greece, which, in its beautifully symmetrical statues, has left us undoubted evidence that it had little to learn in the science of training the body.

Colonel Fox went on to say that the Greeks practised little of what we understand as gymnastics, and attained their object by such exercises as riding, dancing, leaping, or running, and he pointed out that the trend of gymnastic opinion is again turning strongly in the same direction. As the power of Greece declined, her universal physical culture ceased to be national, and passed to the individual whose business it. was to afford entertainment by exhibiting his prowess in the arena. When the remnants of greatness passed to Rome, no physical training became general, as the many contented themselves with the excitement afforded by the efforts of the trained few. It is true that the "sporting nobles" of the famous Tenth Legion used from time to time to descend into the arena, competing with some favourite team in the chariot races, or matching their skill with sword and shield against the net and trident. This action was, however, exceptional, and the period bears the picture of a vast concourse hanging with fevered excitement on every stroke of sword or cast of net-spectators at a game that they themselves had little ability or desire to play. To find a modern parallel to such a scene we have unfortunately not far to seek.

After touching on the absence of any definite system of gymnastics also in the middle ages, ard the recommendation of exercises as a cure for certain complaints as early as the sixteenth century, the reader of the paper traced the use of systems in France, in Germany, where gymnastics were first used in an educational sense, in Switzerland, where Pestalozzi adopted them, and in Sweden, where between 1776 and 1839 Ling was the pioneer in classifying gymnastics into groups and arranging them scientifically in accordance with the needs of the human body.

Colonel Fox described how, after an interregnum, revivals of physical training took place, and stated that under the tests of modern physiological knowledge the Swedish system of Ling stands out preeminently above all others. $\mathrm{He}$ further dwelt on the mild and gradual work in its early stages, on its effects upon the body and success in other countries, as well as its educational results. These admit of no immediately apparent proof, but they do exist, as a few weeks' trial of them will most assuredly show: Psychology, Coloned Fox said, with our limited knowledge, allows of deductions only from experience, and the latter is unanimous that the educational results claimed by Ling are gained, and that the qualities of courage, obedience, decision, alertness, concentration of thought and self-confidence are not confined to the hour or two of the gymnastic lesson, but become part and parcel of the child's nature.

After speaking of methods, duration of lessons, the dearth of male teachers, and matters of interest to elementary and other teachers, Colonel Fox concluded by quoting figures from the report of a Royal Commission on Physical Education in Scotland. Of 600 children examined in Aberdeen, only 326 were found to be in good health, while of the same number in Edinburgh but $17 x$ were found to be sound.

The next paper was by Mr. W. Langbridge (headmaster of Wolverley Street School, Bethnal Green), and dealt with exercises which can with advantage be performed in classrooms and afford a relief to ordinary lessons during which activities are constrained.

In the afternoon Sir Lauder Brunton took the chair, and discussed education in connection with the threefold character of man. At first, he said, moral training was provided, and churches and cathedrals were built long before the people could read or write; then mental culture was considered, and became very general; and, lastly, it was being recognised that the condition of the body had considerable effect upon the morals and the mind, so that a physical training was also considered necessary. He gave some interesting instances to show how character 